Article

\title{
Campaign Duration and Election Outcomes
}

Costas Panagopoulos

Department of Political Science, Fordham University, Bronx, NY 10458, USA; E-Mail: costas@post.harvard.edu; Tel.: +1 7188173967; Fax: +1 7188173972

\section{How to Cite this Article}

Panagopoulos, C. (2013). Campaign Duration and Election Outcomes. Politics and Governance, 1(1), 66-73.

\section{Acknowledgement}

This Article was published by Librello, Politics and Governance's former publisher.

\section{About the Journal}

Politics and Governance is an innovative new offering to the world of online publishing in the Political Sciences. An internationally peer-reviewed open access journal, Politics and Governance publishes significant, cutting-edge and multidisciplinary research drawn from all areas of Political Science.

www.cogitatiopress.com/politicsandgovernance

\section{Editors-in-Chief}

Professor Andrej J. Zwitter, Faculty of Law, University of Groningen, The Netherlands

Professor Amelia Hadfield, Department of Psychology, Politics and Sociology, Canterbury Christ Church University, UK

\section{Managing Editor}

Mr. António Vieira, Politics and Governance, Cogitatio Press, Portugal 


\title{
Campaign Duration and Election Outcomes
}

\author{
Costas Panagopoulos \\ Department of Political Science, Fordham University, Bronx, NY 10458, USA; E-Mail: costas@post.harvard.edu; \\ Tel.: +1 7188173967; Fax: +17188173972
}

Submitted: 15 January 2013 | In revised form: 28 March 2013 | Accepted: 2 May 2013 |

Published: 23 May 2013

\begin{abstract}
Does campaign duration affect election outcomes? To date, this question has largely evaded political scientists, but it is reasonable to expect systematic links between campaign length and candidate performance in elections. We hypothesize that longer campaigns would help challengers' electoral fortunes, thereby curbing incumbency advantage and potentially boosting competitiveness in elections. Using two data sources, aggregate data from U.S. House elections between 1994 and 2006 and ANES survey data from the 2002 election cycle, we find little evidence to support contentions that campaign length affects election outcomes or candidate familiarity. The results we report suggest the political consequences, intended or not, to choices about election timing are likely minimal.
\end{abstract}

Keywords: campaign duration; campaign length; campaign spending; campaign timing; candidate familiarity; election outcomes; vote choice

\section{Introduction}

On 28 October 2009, President Barack Obama signed into law the Military and Overseas Voter Empowerment (MOVE) Act, an initiative designed to help military serving overseas and citizens who live abroad to vote in U.S. elections. Among other provisions, the law requires states to send absentee ballots to voters overseas at least 45 days in advance of any federal election, including special, primary and runoff elections. As a practical matter, this provision has been problematic for several states which have typically held late congressional primary elections, often in September, to determine general election candidates for Congress. The Department of Defense has been reluctant to grant states waivers to this requirement, so states have revamped their electoral calendars to hold primary elections earlier in the election cycle.

Ostensibly, MOVE was designed to enfranchise American voters living or serving in the military abroad, but the Act, which went into effect during the November 2010 elections, will undoubtedly have other consequences, intended or otherwise. One implication linked to this policy reform, and alluded to above, is that general election periods are likely to be lengthened, at least for some elections in several states. But what are the political consequences potentially associated with longer campaigns? To date, this question has largely evaded political scientists, but it is reasonable to expect systematic links between 
campaign duration and candidate performance in elections. One possibility is that longer campaigns would help challengers' electoral fortunes, thereby curbing incumbency advantage and boosting competitiveness in elections. In this paper, we investigate this possibility empirically by examining data from U.S. House elections between 1994 and 2006. Previewing our main findings, we find evidence that campaign duration does impact election outcomes, suggesting there are important consequences, intended or not, to choices about election timing. We also speculate about the underlying mechanism that potentially gives rise to this pattern. We analyze survey data from the 2002 American National Election Study to demonstrate that longer campaigns may advantage candidates at the polls by raising awareness about them and elevating name recognition. This effect appears to be moderated by levels of campaign spending.

\section{Incumbency and Campaign Length}

Incumbent dominance at the polls has long been a central and enduring feature of American elections. Scholars have traced incumbent strength to a number of sources [1-3], but an advantage in incumbent name recognition has emerged as a leading explanation [4]. As Jacobson notes, "people hesitate to vote for candidates they know nothing at all about. Among the most consistent findings produced by studies of congressional voters over the past generation is that simple knowledge of who the candidates are is strongly connected to voting behavior" [4].

Discussions about the impact of name recognition on voting preferences are often closely linked to ongoing debates about the deployment of candidate resources, most notably campaign funds. On this score, researchers have been somewhat equivocal. Some [5-8] argue that spending by challengers is more effective than spending by incumbents, perhaps reflecting the relative obscurity of challengers. Others [9-12] find incumbent and challenger spending to have similar effects, with challengers enjoying a smaller edge in spending efficiency than suggested initially by Jacobson [5]. The problem of reciprocal causation resulting from strategic behavior by candidates and donors alike makes the precise relationship between spending and election results difficult to pin down, but most studies suggest marginal returns are greater for challengers than for incumbents [4]. Taken as a whole, these findings imply that policies that grant equal resources to both incumbents and challengers would advantage challengers because of diminishing marginal returns, a hypothesis that finds supports in recent field experimental work [13].

Despite an abundance of studies published over several decades devoted to disentangling the impact of campaign spending on election outcomes, examinations of the impact of access to other important resources, like time, are scarce. After all, time can facilitate information acquisition, and scholars have shown the length of a campaign helps voters to make use of important electoral information [14]. Moreover, unlike campaign spending, whose causal effects are methodologically challenging to isolate because they can be linked to expected outcomes, the duration of a campaign is exogenously determined and assigned in an even-handed manner to all candidate types in a given state. As we demonstrate below, the duration of campaigns varies considerably over time and across states, and this variation can be exploited to gauge the effects of this important resource on candidate voteshares.

Given the discussion above, we hypothesize that longer campaigns would disproportionately advantage challengers over incumbents. Longer campaigns would conceivably afford challengers greater opportunities to build awareness of their candidacies and to cut into incumbents' name recognition advantages. In this study, we investigate this possibility using data from elections for the U.S. House of Representatives between 1994 and 2006. We find support for the contentions that campaign duration affects election outcomes and that longer campaign cycles benefit challengers over incumbents. We also find that the impact of campaign duration is moderated by the level of campaign funds.

We proceed as follows. In the next section, we develop more fully our ideas about the impact of campaign duration on election outcomes and provide a more nuanced set of hypotheses. We then describe the variation in campaign duration in states across the country over the period of our study. In the following section, we develop and estimate an empirical model to test our hypotheses and present the results. We conclude with a discussion of the implications of our findings.

\section{The Impact of Campaign Length: Theory and Hypotheses}

Evidence from studies of presidential elections has demonstrated that candidate preferences rarely shift dramatically over the course of a general election campaign, but that meaningful change can, and typically does occur [15]. Preferences form, crystallize or change as a result of learning that is facilitated over the course of a campaign [16]. As Gelman and King [17] argue, campaigns convey information about the values of "fundamental" variables; campaign activities increase the amount of information accessible to voters about candidates' true positions on issue priorities as well as about the real conditions of important considerations (like economic performance). The authors assert that campaigns help to "enlighten" voters, but such an educating process takes time [17]. As Stevenson and Vavreck ([14], p. 223) argue, "[w]ithout sufficient time for this kind of process, voters will be hard pressed to correct distortions in their initial assessments which may be based on a very limited amount 
of information and only a few campaign messages. [E]nlightenment should be less successful in very short election campaigns than it is in campaigns of sufficient length."

A condition that, according to [17], is essential to facilitating enlightenment is competition. Competitive elections, like the presidential contests that the authors study, ensure that biased information cannot systematically misinform voters. But Stevenson and Vavreck ([14], p. 222) argue that symmetry and pervasiveness are linked to competitiveness. "Without symmetry, resource-rich candidates can dominate the information that is conveyed to voters and so might be able to mislead them systematically about the true values and weights for fundamental variables that are unfavorable to them." Related is pervasiveness, which the authors conceive of as the ability to reach the bulk of the electorate with their campaign messages. Using data from 113 elections in 13 democracies, Stevenson and Vavreck show that voters rely more heavily on the true values of economic conditions to inform their preferences in relatively lengthy campaigns of at least six weeks while these effects are largely absent in shorter campaigns; they conclude campaign length matters for voter learning [14].

If it is the case that campaign length helps voters to learn about important aspects of a campaign, like candidate qualities and positions on key issues, then longer campaigns presumably afford challengers greater opportunities to make up for deficits in familiarity or name recognition they typically start off with [4], relative to incumbents; sufficiently long campaigns should, all else equal, disproportionately favor challengers. This is the main hypothesis we investigate below.

But longer campaigns, in and of themselves, are not necessarily sufficient to accrue benefits to challengers. Unlike the presidential contests that Gelman and King [17] study, congressional elections are typically lopsided affairs characterized by resource imbalances: "symmetry", at least with respect to financial resources, is uncommon in races against incumbents in particular [4]. Above we argue that sufficient campaign length has the capacity to afford nonincumbents the time to become more familiar to voters, but even challengers with the luxury of longer campaign periods may not necessarily be able to capitalize on these without adequate resources. It is also conceivable that any potential benefits associated with longer campaigns may be less influential for well-funded challengers. Considerable financial resources at their disposal may render campaign duration less consequential with respect to its influence on eventual levels of support at the polls. Conversely, challengers with scant financial resources may benefit more so from longer periods during which to promote their candidacies. Accordingly, we argue the effect of campaign duration on candidate performance will be moderated by the level of campaign spending, a conditional hypothesis we examine empirically below.

\section{Measuring Campaign Duration}

The measurement of campaign duration can itself be a debatable matter. In contemporary presidential nomination contexts, the notion of an "invisible primary" that often begins long before any votes are cast in an actual election is an established regularity. For the purposes of the current study, we are concerned primarily with the length of the formal general election campaign period, which we define as the total number of calendar days between the primary election and the general election. This choice is arbitrary, and it is not intended to discount the significance of the informal campaign period that typically unfolds in advance of primary Election Day, sometimes over a span of months or even years. Admittedly, this is a crude measure that does not take into account a myriad of other factors that could include whether eventual nominees faced contested primaries, how soon before the primaries candidates declared their candidacies or actually began to campaign, or variation in convenience voting or levels of early, absentee or mail-in voting in each jurisdiction. While research examining the effects of these factors is worthwhile in its own right, we acknowledge these limitations and view the current study as a first-cut in examining the heretofore unexplored relationship between campaign duration and outcomes. As such, we are mainly interested here in the period beyond the primary election, when candidates have secured party nominations and are assured positions on general election ballots.

Despite the fact that a uniform date for congressional general elections has been statutorily set by Congress since 1872 (for the Tuesday after the first Monday in November of even-numbered years), regulations concerning primary elections, including dates on which these contests are held, are reserved for the states. As a result, there is considerable variation, both over time and across states in terms of primary election dates. Researchers have observed that, over the past few decades, states seeking greater influence in presidential nomination contests have moved their primary dates earlier and earlier in the process [18], resulting in the so-called frontloading phenomenon, but primary elections for congressional candidates need not necessarily coincide with presidential primaries; they often do not. As a result, the duration of the general election campaign period, in terms of total number of calendar days, for congressional races varies considerably both across states and within states over time.

Table 1 presents further evidence about the variation in the mean duration of the general election period, as well as the range, for congressional election cycles between 1994 and 2006. The data for the period we examine indicate that general election candidates 
Table 1. Congressional general election duration (days), 1994-2006.

\begin{tabular}{cccc}
\hline Year & Mean (Days) & Minimum & Maximum \\
\hline 1994 & $122(60)$ & 14 & 245 \\
1996 & $118(58)$ & 21 & 239 \\
1998 & $114(55)$ & 45 & 238 \\
2000 & $129(64)$ & 45 & 245 \\
2002 & $116(57)$ & 43 & 245 \\
2004 & $125(63)$ & 45 & 245 \\
2006 & $122(54)$ & 45 & 245 \\
\hline
\end{tabular}

Note: Standard deviations in parentheses.

have consistently had about four months on average to campaign, but this span of time varies widely. In the 1990s, congressional candidates in Arkansas, for example, had only two or three weeks to campaign against their general election opponents, while candidates in states like Ohio, Texas and Illinois had almost eight months to do so. In the most recent cycles we examine, the length of the general election period ranges from about six weeks to eight months [19].

Above we argue that this variation may have important consequences for election outcomes. Candidates, namely challengers, may be able to take advantage of longer campaign periods to build name recognition and awareness and to promote their candidacies, while incumbents would presumably have an advantage in shorter campaign cycles. We also expect the impact of campaign duration will be moderated by the level of campaign funds accessible to a challenger. Next we proceed to estimate the impact of campaign duration on candidate performance.

\section{Estimating the Impact of Campaign Duration on Candidate Performance}

Previous research has established that candidate voteshares in general elections are a function of a number of factors including resource levels, district partisan strength and candidate quality [4]. As we discuss above, reciprocal causation between campaign spending and expected voteshares make empirical examinations of the impact of campaign spending on election outcomes a methodologically thorny issue. Scholars have grappled with this issue for decades [4-7,9-12] offering a range of solutions. Most of these studies advocate, and several adopt, an instrumental variables approach to addressing the issue of reciprocal causation, although the range of instruments for spending variables is diverse across studies. In the current study, we adopt an empirical strategy similar to the one proposed by Green and Krasno $[9,10]$. Specifically, we use lagged incumbent spending as an instrument for current incumbent spending in two-stage least squares analyses. To be consistent with previous work in this field, we also adopt the following conventions: first, we convert all spending figures to 2006 dollars; as in previous studies, a log transformation of campaign spending (in thousands of 2006 dollars) is used to simulate diminishing marginal returns; to make this assumption less drastic, $\$ 5,000$ is added to all candidate expenditure levels (see [7] for details). A similar transformation was performed on the incumbent spending instrument (incumbent spending in the previous campaign). Two-stage least squares purges the independent variables of their covariance with the disturbance term; the procedure involves estimating a predicted score for the endogenous regressor (the incumbent spending variable), in this case, from its lagged values, and using this as instruments in a second-stage regression instead of the original value.

To isolate the impact of campaign duration on candidate performance in general elections, we include measures of campaign duration in a more fully specified model that simultaneously accounts for other variables, as discussed above, known to influence candidate voteshares in elections. We estimate a series of two-stage least squares regression models using the instrument for incumbent spending described above [20]. The basic model presents the challenger's share of the two-party vote in contested general elections as a function of incumbent (instrumented) and challenger campaign spending, challenger quality, and incumbent party strength in the district and campaign duration. We also include a dummy variable in the model to account for presidential election years as well as indicators to denote the party of the challenger and redistricted districts; we interact the challenger party indicator with dummy variables for each year included in our study to account for national, partisan trends. Consistent with previous work, we adopt a dichotomous categorization for challenger quality [4]; admittedly, a more refined measure of quality would have been preferable, however this was unavailable. Studies have repeatedly demonstrated such dichotomous conceptualizations of challenger quality to be quite robust and very highly correlated with alternative, more refined measures of quality [7]. Accordingly, we consider challengers with prior elective experience to be high-quality challengers while those with no prior elective office are low-quality.

The results of the initial estimation, model 1 presented in Table 2, column 1, reveal patterns that are familiar given extant work in this field. We find evidence that challenger performance is strengthened by higher levels of both incumbent and challenger spending as well as challenger party strength in the district and challenger experience. The results also suggest challengers are disadvantaged somewhat in presidential years.

Our key variable of interest, however, is the duration of the general election period, operationalized as the total number of calendar days between the primary and general elections. We estimate a second model (model 2 ) that adds this variable to the equation. The results of the estimation are presented in Table 2, column 2 . The estimates reveal that the inclusion of the additional 
Table 2. Estimating the impact of campaign duration on candidate performance.

\begin{tabular}{|c|c|c|c|}
\hline \multirow[b]{2}{*}{ Variable } & \multicolumn{3}{|c|}{ Model Specifications } \\
\hline & (1) & (2) & (3) \\
\hline $\begin{array}{l}\text { Challenger Party Strength in } \\
\text { District }\end{array}$ & $0.384(0.012)^{* * *}$ & $0.384(0.012)^{* * *}$ & $0.386(0.012)^{* * *}$ \\
\hline Experienced Challenger & $1.143(0.303)^{* * *}$ & $1.160(0.303)^{* * *}$ & $1.142(0.304)^{* * *}$ \\
\hline $\begin{array}{l}\text { General Election Duration } \\
\text { (days) }\end{array}$ & & $0.002(0.002)$ & $0.003(0.026)$ \\
\hline $\begin{array}{l}\text { Incumbent Spending (log) } \\
\text { (instrument) }\end{array}$ & $1.281(0.278)^{* * *}$ & $1.309(0.278)^{* * *}$ & $1.158(0.663)$ \\
\hline $\begin{array}{l}\text { Incumbent Spending (inst.) } \\
\times \text { Duration }\end{array}$ & & & $0.001(0.004)$ \\
\hline Challenger Spending (log) & $2.384(0.073)^{* * *}$ & $2.380(0.073)^{* * *}$ & $2.630(0.150)^{* * *}$ \\
\hline $\begin{array}{l}\text { Challenger Spending (log) } \\
\times \text { Duration }\end{array}$ & & & $-0.002(0.001)^{* *}$ \\
\hline Challenger Democrat & $1.606(0.575)^{* * *}$ & $1.592(0.574)^{* * *}$ & $1.592(0.574)^{* * *}$ \\
\hline Presidential Election Year & $-5.898(0.540)^{* * *}$ & $-6.032(0.518)^{* * *}$ & $-6.023(0.518)^{* * *}$ \\
\hline Redistricted & $0.925(0.613)$ & $0.891(0.612)$ & $0.900(0.613)$ \\
\hline Constant & $2.918(1.783)$ & $2.394(1.807)$ & $2.263(4.258)$ \\
\hline$N$ of individuals & 1,666 & 1,663 & 1,674 \\
\hline Adjusted R-squared & 0.771 & 0.772 & 0.773 \\
\hline
\end{tabular}

Notes: Two-least least squares regression (TSLS). In the first stage, incumbent spending (logged) is estimated as a function of lagged incumbent spending (logged). These estimates are then used as instruments for incumbent spending in the second stage in which the dependent variable is the challenger's share of the two-party vote in the district. Standard errors in parentheses. ${ }^{* * *}$ denotes statistical significance at the $\mathrm{p}<0.01$ level, and $* *$ at the $\mathrm{p}<0.05$ level, using two-tailed tests. All models include dummy variables for years and year/challenger party interactions (not shown; available upon request). Redistricting years $(1992,2002)$ excluded. See text for details about spending and other variable measurement or construction.

variable denoting the duration of the general election campaign does not substantively alter the impact or statistical significance of any of the other variables. The coefficient for the campaign duration variable is positive, implying longer campaigns may boost challenger voteshares relative to incumbents, but the effect is not statistically significant; moreover, it is, at best, substantively modest. Extending the general election period by 100 days would only add 0.2 percentage points on average to the challenger's voteshare, all else equal.

We remind readers, however, that we expect the impact of the length of the campaign to be conditioned by the level of campaign spending. Thus, we estimate a third model (model 3) to include interaction terms in our model to capture the effects of campaign duration as conditioned by candidate spending levels in addition to the individual constitutive terms accordingly. The estimates reveal some familiar results: support for challengers is positively and significantly influenced by prior experience and partisan strength in the district, as in the other two models. However, neither incumbent spending (instrumented) nor the interaction between campaign duration and incumbent spending are statistically significant, suggesting incumbent spending levels are statistically unrelated to challenger performance once the other ingredients are included in the model. The positive and significant impact of challenger spending persists, however. The direct effect of the campaign duration variable remains insignificant, however the interaction between challenger spending and campaign duration is statistically significant at conventional levels, implying the impact of campaign length is moderated by the level of challenger spending, as hypothesized above. The negative and statistically significant coefficient on the interaction term, however, suggests the effect of campaign duration declines as challenger spending grows. We interpret this to suggest the marginal impact of campaign length declines with growing levels of campaign spending, a result that is also consistent 
with the hypothesis we develop above. Still, the substantive effects are quite small. Figure 1 presents a visual depiction of the impact of campaign duration on challenger voteshares across ranging of levels of logged challenger spending. The solid line displays the marginal impact of campaign duration on challenger support at the polls, with dashed lines representing the 95 percent confidence intervals associated with the impact of campaign duration for the corresponding spending levels. Taking uncertainty levels into account, the evidence indicates the marginal impact of campaign duration is indistinguishable from zero. Although there are indications the marginal effect of campaign length likely declines somewhat as spending grows, the overall effect is negligible. Next, we proceed to examine the impact of campaign length on candidate familiarity.

\section{Estimating the Impact of Campaign Duration on Candidate Familiarity}

Above we argued that the length of congressional general election campaigns likely influences challenger performance at the polls on Election Day. The analyses we present, however, provide only limited empirical evidence for this contention; for the most part, the effects are likely substantively small, at best. To the extent that longer campaigns may influence candidate voteshares in elections, however, what could be the driving force behind any such effects? One possible underlying mechanism that could give rise to the hypothesized effect is that longer campaigns facilitate voter learning and raise familiarity with challengers. Previous research has established a link between familiarity and vote choice and demonstrated that greater familiarity increases the likelihood of voting for a candidate $[4,21]$. If the likelihood of voting for a challenger is enhanced because longer campaigns raise challenger familiarity, we should be able to detect empirical evidence for the latter. Accordingly, we expect that longer campaigns raise voters' familiarity with the candidates, especially challengers, cutting into the recognition advantage incumbents typically enjoy [4] and that this is the causal mechanism that may help to explain even the muted effects on electoral support we identify above. Next, we seek empirical evidence for the contention that longer campaigns raises candidate familiarity, even after controlling for other key factors like candidate quality and campaign spending.

We rely on data collected for the 2002 American National Election Study for these analyses. The 2002 ANES probed respondents about their ability to recognize congressional candidates in the November 2002 elections. Analysis of the unweighted data confirms incumbents' recognition advantage compared to challengers: 89 percent of respondents recognized incumbents, compared to only 58 percent who could recognize challengers. We expect longer campaigns could conceivably boost levels of recognition for incumbents, but we argue that longer campaigns should elevate challenger recognition levels even more so.

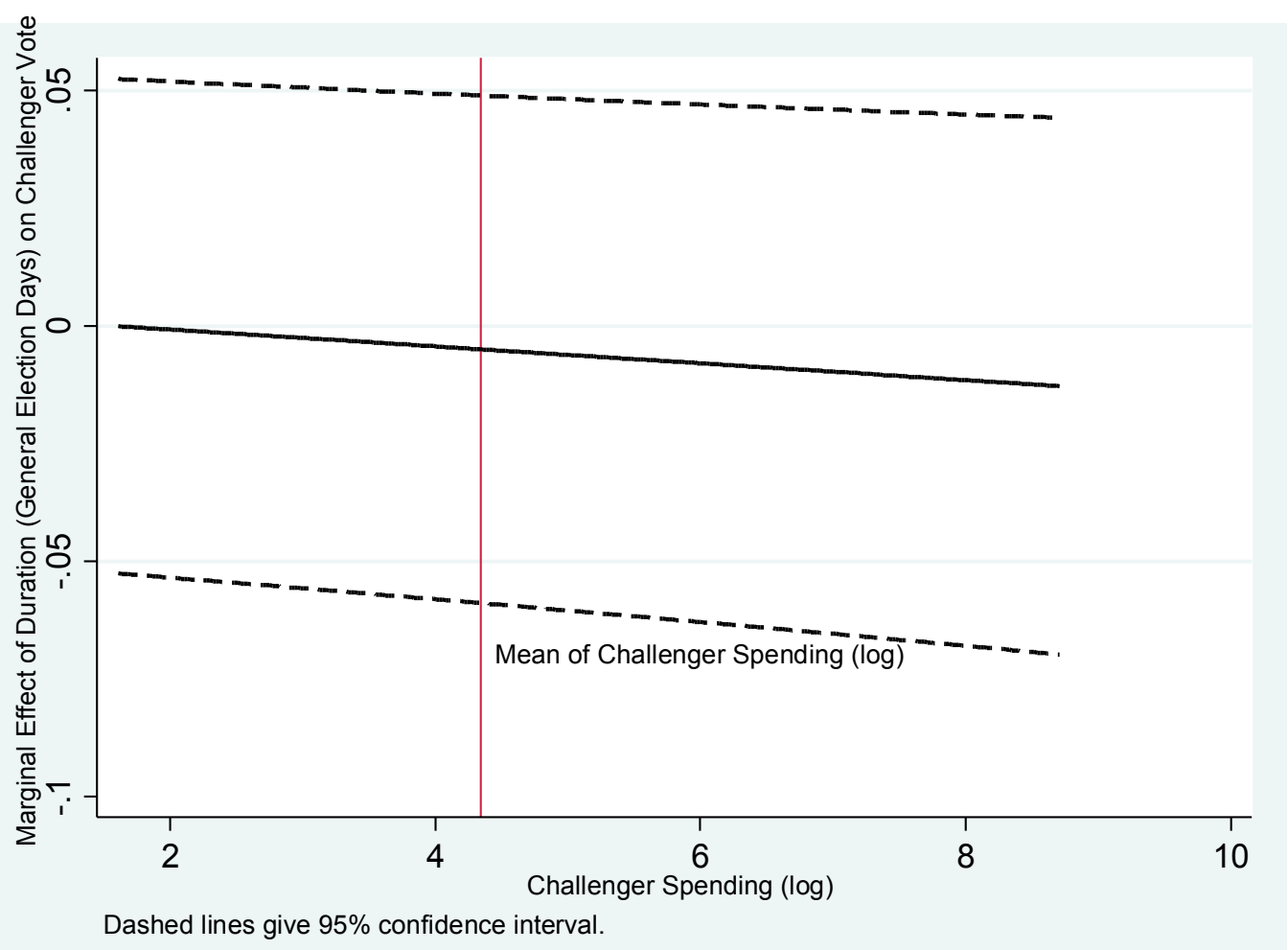

Figure 1. Marginal impact of campaign duration on challenger voteshares across range of challenger spending (logged) levels. 
Table 3. Estimating the impact of campaign duration on candidate familiarity.

\begin{tabular}{|c|c|c|}
\hline & Recognize Challenger & Recognize Incumbent \\
\hline \multicolumn{3}{|l|}{ Variable } \\
\hline $\begin{array}{l}\text { Incumbent spending } \\
\text { (thousands of dollars, logged) }\end{array}$ & $0.031(0.323)$ & $0.134(0.423)$ \\
\hline $\begin{array}{l}\text { Challenger spending } \\
\text { (thousands of dollars, logged) }\end{array}$ & $0.209 * *(0.103)$ & $0.015(0.139)$ \\
\hline Experienced challenger & $0.489 * * *(0.163)$ & $-0.066(0.211)$ \\
\hline $\begin{array}{l}\text { Candidate Party Strength in } \\
\text { District }\end{array}$ & $0.019 * * *(0.007)$ & $0.004(0.009)$ \\
\hline $\begin{array}{l}\text { General Election Duration } \\
\text { (days) }\end{array}$ & $-0.001(0.013)$ & $-0.003(0.016)$ \\
\hline $\begin{array}{l}\text { Duration } \times \text { Incumbent } \\
\text { Spending }\end{array}$ & $0.0005(0.002)$ & $0.0003(0.003)$ \\
\hline $\begin{array}{l}\text { Duration } \times \text { Challenger } \\
\text { Spending }\end{array}$ & $-0.0001(0.0006)$ & $0.00003(0.001)$ \\
\hline Constant & $-2.606(2.065)$ & $-0.025(2.691)$ \\
\hline$N$ & 509 & 537 \\
\hline Pseudo R-squared & 0.16 & 0.11 \\
\hline Log likelihood: & -278.972 & -147.119 \\
\hline $\begin{array}{l}\text { Notes: Probit regression (unweight } \\
\text { coded } 1 \text { if respondent accurately } \\
\text { statistical significance at the } p<.01 \\
\text { include the following political and d } \\
\text { gender, race, income, education, } \\
\text { partisanship of the challenger (as we } \\
\text { upon request). Source: [22] }\end{array}$ & $\begin{array}{l}\text { Standard errors in parent } \\
\text { ggnized challenger/incumbe } \\
* * \text { at the } p<05 \text { level, usin } \\
\text { graphic control variables ( } \\
\text { cher respondent was marr } \\
5 \text { its interaction with respon }\end{array}$ & $\begin{array}{l}\text { eses. Dependent variable is } \\
\text { t, } 0 \text { otherwise. } * * * \text { denotes } \\
\text { two-tailed tests. Models also } \\
\text { t shown): partisanship, age, } \\
\text { d or resided in the South; } \\
\text { ent party ID; details available }\end{array}$ \\
\hline
\end{tabular}

We append the ANES data to include campaign variables shown to influence familiarity (campaign spending levels (logged) [23], candidate quality, partisan composition of district) as controls (see [4]); we also control for key political and demographic attributes including a dummy variable to denote the challenger's party (in addition to its interaction with a respondent's partisan identification), partisanship, age, race, gender, income, education, whether respondents were married or resided in the South. The key variable of interest is the length of the general election campaign, measured in total number of days between the primary and general elections as above. Again, we expect recognition to be positively related to campaign length; consistent with arguments developed above, we hypothesize further that the impact of campaign duration will depend on the level of campaign expenditures. We include terms in our models to test these hypotheses, including interactions. We use probit regression to estimate models to predict respondents' ability to recognize a candidate (incumbents and challengers separately) as a function of these variables and the interactions.

The results of the estimations are presented in Table 3. We find that challenger recognition is explained by challenger spending and experience and the district's partisan tendencies. The estimates reveal that neither challenger nor incumbent recognition is influenced by campaign duration; the interactions are also statistically insignificant, suggesting there is no heterogeneity in the impact of campaign length attributable to spending levels. Jacobson demonstrated that support for U.S. Senate challengers in the 2000 elections grew over time during the course of the campaign cycle in direct proportion to spending, but the author did not examine elements related to campaign duration [20]. Jacobson also demonstrated that incumbent familiarity and favorability were not linked to levels of incumbent spending, a result that is consistent with the estimates reported in column 2 of Table 3 [21]. In fact, we find that incumbent recognition is unrelated to the key factors we investigate including spending, candidate quality, district partisanship or campaign duration, suggesting that sources of familiarity with incumbents differ considerably from forces that influence challenger recognition.

\section{Conclusion}

Overall, the preponderance of empirical evidence we report suggests campaign length may matter little for election outcomes once the effects of other, relevant factors are taken into account. That said, there are hints that campaign duration could exert the hypothesized effects, but additional research is necessary to demonstrate this connection more definitively. We acknowledge the substantive impact of campaign duration is likely quite small, at best, but it may not be wholly irrelevant to candidate performance. Even so, there is scant evidence that 
campaign duration is related to familiarity with the candidates, so the identification of a mechanism by which longer campaigns may help challengers, if it does turn out to be the case, remains elusive. One sobering conclusion readers may reach from the current study is that if a pattern of longer campaign periods emerges in American elections, precipitated by recent policy reforms or otherwise, there are unlikely to be significant electoral consequences. For observers who decry anemic competition in races like congressional contests, longer campaigns will likely not offer a glimmer of hope.

We conclude by acknowledging that the current study and the theoretical arguments we develop raise some intriguing possibilities, but it is beyond the scope of this paper to explore all of the nuances associated with campaign duration. Further research

\section{References and Notes}

1. Erikson RS. The Incumbency Advantage in Congressional Elections. Polity. 1971;3(3):395-405.

2. Carson JL, Engstrom EJ, Roberts JM. Candidate Quality, the Personal Vote, and the Incumbency Advantage in Congress. American Political Science Review. 2007;101(2):289-301.

3. Mayhew DR. Congressional Elections: The Case of the Vanishing Marginals. Polity. 1974;6(3):295-317.

4. Jacobson GC. The Politics of Congressional Elections. 6th ed. New York, NY, USA: Pearson Longman; 2004.

5. Jacobson GC. The Effect of Campaign Spending in Congressional Elections. American Political Science Review. 1978;72(2):469-491.

6. Jacobson GC. Money and Votes Reconsidered: Congressional Elections 1972-1982. Public Choice. 1985;47(1):7-62.

7. Jacobson GC. The Effects of Campaign Spending in House Elections: New Evidence for Old Arguments. American Journal of Political Science. 1990;34(2): 334-362.

8. Abramowitz AI. Incumbency, Campaign Spending, and the Decline of Competition in U.S. House Elections. Journal of Politics. 1991;53(1):34-56.

9. Green DP, Krasno JS. Salvation for the Spendthrift Incumbent: Reestimating the Effects of Campaign Spending in House Elections. American Journal of Political Science. 1988;32(4):884-907.

10. Green DP, Krasno JS. Rebuttal to Jacobson's 'New Evidence for Old Arguments'. American Journal of Political Science. 1990;34(2):363-372.

11. Levitt SD. Using Repeat Challengers to Estimate the Effect of Campaign Spending on Election Outcomes in the U.S. House. Journal of Political Economy. 1994;102(4):777-798.

12. Erikson RS, Palfrey TR. Equilibria in Campaign Spending Games: Theory and Data. American Political Science Review. 2000;94(3):595-609.

13. Panagopoulos C, Green DP. Field Experiments could propose a more refined measure of campaign duration that takes into account the dynamics of the primary period or early voting. Additional work could also contribute deeper insights about how campaign length operates with other aspects of elections to influence outcomes. For instance, does the timing of campaign appearances differ depending on campaign length? How does news coverage of challengers and incumbents vary depending on campaign length? How does having a contested primary interact with these other factors? Do contested primaries give challengers a leg up by getting them early media exposure? Or do contested primaries prevent candidates from beginning their general election campaigns, ultimately hindering their chances of success? The central mechanisms linking campaign length and candidate success are complicated and beg further scholarly examination.

Testing the Impact of Radio Advertisements on Electoral Competition. American Journal of Political Science. 2008;52(1):156-168.

14. Stevenson RT, Vavreck L. Does Campaign Length Matter? Testing for Cross National Effects. British Journal of Political Science. 2000;30(2):217-235.

15. Wlezien $\mathrm{C}$, Erikson RS. The Timeline of Presidential Election Campaigns. Journal of Politics. 2002;64(4):969-993.

16. Erikson RS, Panagopoulos C, Wlezien C. The Crystallization of Voter Preferences during the 2008 Presidential Campaign. Presidential Studies Quarterly. 2010;40(3):482-496.

17. Gelman A, King G. Why Are American Presidential Election Polls So Variable When Votes Are So Predictable? British Journal of Political Science. 1993;23(4):409-451.

18. Mayer WG, Busch AE. The Front-loading Problem in Presidential Nominations. Washington, DC, USA: Brookings Institution Press; 2004.

19. We note there do not appear to be any firm patterns over time; if anything, general election campaign periods appear to be growing slightly over the time horizon we examine, but this trend is not statistically significant at conventional levels. Data available upon request.

20. We note we obtain substantively similar conclusions for the analyses using ordinary least squares without instrumented incumbent spending. Details available upon request.

21. Jacobson GC. Campaign Spending Effects in U.S. Senate Elections: Evidence from the National Annenberg Election Survey. Electoral Studies. 2006;25(2):195-226.

22. The American National Election Studies. The 2002 Time Series Study. Ann Arbor, MI, USA: University of Michigan; 2002.

23. We do not adopt a two-stage least squares estimation approach using lagged incumbent spending as an instrument in these analyses given 2002 was a redistricting year and district. 